\section{AB0960 GROWTH AND SEXUAL MATURATION IN GIRLS WITH JUVENILE IDIOPATHIC ARTHRITIS}

L.M. Gonçalves ${ }^{1}$, S.H. Machado ${ }^{2}$, R.M. Xavier ${ }^{3}$, P.J.C. Maróstica ${ }^{4}$, P. Lora ${ }^{5}$, L. Trindade ${ }^{5} .{ }^{1}$ student, PUCRS; ${ }^{2}$ Rheumatology service, HCPA; ${ }^{3}$ Rheumatology service, UFRGS; ${ }^{4}$ Pediatrics service, UFRGS/Hcpa; ${ }^{5}$ Unisinos, Porto Alegre, Brazil

Background: Juvenile idiopathic arthritis (JIA) is a heterogeneous group of diseases with onset before the age of 16 years and joint inflammation as a main feature. Longitudinal growth is one of the main physical changes in childhood and adolescence. The etiology of delayed growth in children with JIA is multifactorial and strongly associated with prolonged inflammatory activity.

Objectives: To evaluate growth, sexual maturation, and the difference between final and expected height in girls with JIA and no glucocorticoid treatment for at least six months, as compared to a group of healthy girls.

Methods: This cross-sectional study involved 44 girls with JIA, diagnosed according to International League of Associations for Rheumatology (ILAR) criteria, and 59 healthy controls, aged between eight and 18 (incomplete) years with no comorbid chronic diseases. Demographic data were collected from all participants, and disease and treatment variables were compiled for the patient group. Anthropometric measurements were converted into z-scores based on WHO standards. Sexual maturation was classified according to Tanner stages. Results: BMI and height z-scores were lower in girls with JIA as compared to control participants. These values differed significantly in Tanner stage II. Three $(6.8 \%)$ girls with JIA had height-for-age $z$-scores $<-2$ (short stature). Girls with polyarticular JIA and higher cumulative glucocorticoid doses were significantly more likely to present with short stature. The percentage of prepubertal girls in the JIA group was significantly higher than that observed in the control group, $(p=0.012)$. Age of menarche, adult height, and the difference between actual and expected height did not differ between groups.

Table 1. Comparison of pre- and postmenarcheal growth parameters between groups

\begin{tabular}{lccc}
\hline Variables & $\begin{array}{c}\text { Patients }(\mathrm{n}=44) \\
\text { Mean } \pm \text { SD }\end{array}$ & $\begin{array}{c}\text { Control participants }(\mathrm{n}=59) \\
\text { Mean } \pm \mathrm{SD}\end{array}$ & $p$ \\
\hline Menarche $-\mathrm{n}(\%)$ & $17(38.6)$ & $37(62.7)$ & 0.026 \\
Age of menarche (years) & $12.2 \pm 1.51$ & $11.5 \pm 1.24$ & 0,066 \\
Menarche $>$ years $-\mathrm{n}(\%)$ & $13 / 17(76.5)$ & $22 / 37(59.5)$ & 0.363 \\
$\Delta$ Target height (father/mother) & $-3.15 \pm 7.87(\mathrm{n}=8)$ & $1.31 \pm 5.44(\mathrm{n}=16)$ & 0.117 \\
Nutritional data & & & \\
BMl z-score & $-0.10 \pm 1.29$ & $0.92 \pm 1.19$ & 0.007 \\
Height/age z-score & $-0.14 \pm 1.24$ & $0.27 \pm 1.17$ & 0.253 \\
Bone age z-score & $-1.53 \pm 4.29$ & $-1.42 \pm 2.17$ & 0.928 \\
\hline
\end{tabular}

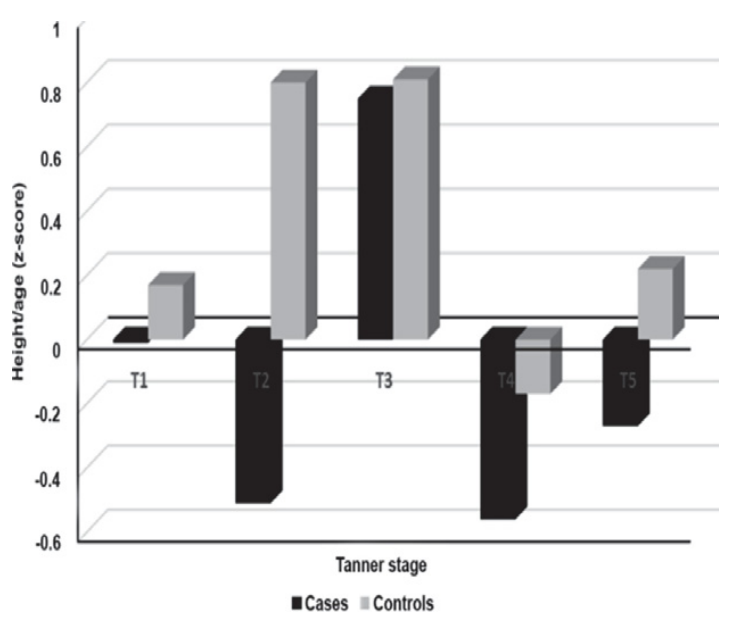

Conclusions: These findings suggest that even six months after the suspension of glucocorticoid treatment, children with more severe forms of JIA and exposure to higher doses of glucocorticoids are still susceptible to growth impairment and delayed puberty.

References:

[1] PETTY RE, SOUTHWOOD TR, MANNERS P, et al.: International League of Associations for Rheumatology classificayion of juvenile idiopathic arthritis: second revision, Edmonton, 2001. J Rheumatol 2004, 31:390-2.

[2] BECHTOLD S, SIMON D: Growth abnormalities in children and adolescents with juvenile idiopathic arthritis. Rheumatol int 2014; 34:1483-8.

[3] GIANNINI C, MOHN A, CHIARELLI F:Growth abnormalities in children with type 1 diabetes, juvenile chronic arthritis, and asthma. Int J Endocrinol 2014; 2014: 265954.

Disclosure of Interest: None declared

DOI: 10.1136/annrheumdis-2017-eular.3016

\section{AB0961 A COHORT OF PATIENTS WITH AUTOINFLAMATORY DISEASES FOLLOWED-UP IN A UNIT OF PAEDIATRIC AND TRANSITIONAL RHEUMATOLOGY: A DESCRIPTIVE STUDY}

A. Boteanu, M. Llop Vilatella ${ }^{1,1}$, M.A. Terán Tinedo, M.Á. Blázquez Cañamero, W.A. Sifuentes Giraldo, M. Vázquez Díaz, M.L. Gámir Gámir. Rheumatology, Hospital Universitario Ramón y Cajal, Madrid, Spain

Background: The autoinflammatory diseases (AD) are uncommon, most of them are presented as episodes of recurrent fever and may be accompanied by other inflammatory symptoms. This group of diseases includes polygenic entities (without a single known genetic mutation) such as Behçet's disease (BD), systemic-onset juvenile idiopathic arthritis (soJIA), Chronic recurrent multifocal osteomyelitis (CRMO) and PFAPA syndrome. On the other hand, we found the entities that present with specific monogenic mutations, such as Familial Mediterranean Fever (FMF), TNF receptor-associated periodic syndrome (TRAPS), hyper-lgD syndrome and periodic fever (HIDS), cryopyrinopathies (FCAS, MWS, CINCA), Blau's syndrome and PAPA. A group of patients who can not be classified into a specific diagnosis are clustered as recurrent fever without known genetic anomaly (RFW).

Objectives: To describe and compare the clinical features of monogenic and polygenic $A D$ and RFW seen in a paediatric and transitional rheumatology unit of a Spanish tertiary care hospital.

Methods: We performed a retrospective study including 39 patients with $A D$ followed-up in our center.

Results: The distribution of diagnoses was: soJIA 19 patients $(48.72 \%)$, BD 5 (12.82\%), PFAPA 6 (15.38\%), CRMO 3 (7.69\%), RFW 4 (10.26\%), HIDS 1 (2.56\%) and CINCA $1(2.56 \%)$. Patients came from different regions of Spain, being 22 of them boys $(56.41 \%)$ and 17 girls $(43.59 \%)$. The genetic study was performed in 12 patients, being positive in 7 (17.95\%). Mean age at onset of symptoms was $5 \pm 5.65$ years in monogenic diseases, $7.96 \pm 4.84$ years in polygenic disorders and $9.5 \pm 5.91$ years RFW. Delay in diagnosis in monogenic diseases was higher than in polygenic diseases $(67 \pm 69.29$ months vs. $24.03 \pm 30.33$ months, respectively). The clinical manifestations more frequently found were fever, followed by joint involvement, being more common in monogenic diseases than in polygenic disorders (table). Haemoglobin levels were lower in monogenic than in polygenic diseases $9.95 \mathrm{~g} / \mathrm{dL} \pm 0.63$ vs. $11.69 \mathrm{~g} / \mathrm{dL} \pm 2$, ESR and CRP was higher in monogenic diseases $106 \mathrm{~mm} / \mathrm{h} \pm 68.5$ and $80.5 \mathrm{mg} / \mathrm{L} \pm 84.14$ vs. $56.1 \mathrm{~mm} / \mathrm{h}$ \pm 33.78 and $57.95 \mathrm{mg} / \mathrm{L} \pm 57.95$, unlike ferritin that was more elevated in polygenic disease $896 \mu \mathrm{g} / \mathrm{dL} \pm 1788.34$ than in monogenic diseases $183 \mu \mathrm{g} / \mathrm{dL}$ \pm 195.7 . During his follow up $84.62 \%$ of patients received corticosteroids, $51.8 \%$ methotrexate and $46.15 \%$ biological therapy.

\begin{tabular}{lccc}
\hline & Monogenic & Polygenic & Recurrent fever \\
\hline Fever & $100 \%$ & $81.25 \%$ & $100 \%$ \\
Joint involvement & $100 \%$ & $62.5 \%$ & $75 \%$ \\
Rash & $100 \%$ & $59.38 \%$ & $0 \%$ \\
Lymphoadenopathy & $50 \%$ & $46.88 \%$ & $25 \%$ \\
Splenomegaly & $100 \%$ & $12.5 \%$ & $0 \%$ \\
Abdominal involvement & $30 \%$ & $21.88 \%$ & $25 \%$ \\
\hline
\end{tabular}

Conclusions: soJIAs was the most frequent $A D$ in our center. All the patients had a similar gender distribution. Delay in diagnosis was greater in monogenic diseases compared with polygenic disorders. Fever and joint involvement were the more common clinical manifestations, especially in monogenic diseases. Ferritin levels were higher in polygenic diseases, whereas CRP and ESR which were higher in monogenic diseases. During the follow-up most patients required treatment with corticosteroids and approximately half of them required biological therapy.

Disclosure of Interest: None declared

DOI: 10.1136/annrheumdis-2017-eular.6912

\section{AB0962 CLINICAL AND LABORATORY CHARACTERISTICS OF NON-BACTERIAL OSTEOMYELITIS: DATA ANALYSIS OF 91 PATIENTS}

M.M. Kostik ${ }^{1}$, O. Kopchak ${ }^{1,2}$, A. Mushkin ${ }^{3} .{ }^{1}$ Saint-Petersburg State Pediatric Medical University, Saint-Petersburg; ${ }^{2}$ Kirov's regional children's hospital, Kirov;

${ }^{3}$ Federal State Budget Institute "Science research Institute of Phthisiopulmonology", Saint-Petersburg, Russian Federation

Background: Non-bacterial Osteomyelitis (NBO) is a sterile inflammatory bone disorder of unknown etiology. It typically affects children and most commonly presents with bone pain and/or swelling.

Objectives: The aim of study is to evaluate clinical and laboratory features of non-bacterial osteomyelitis in children.

Methods: Our retrospective - prospective study was included 91 patients with NBO. A routine blood test (WBC, platelets, ESR, C-reactive protein (CRP) and hemoglobin levels), a radiological examination and a bone biopsy with evaluation bacteriological and morphological data were performed in all patients.

Results: The mean age of onset NBO was 7.3 years $(2.5 ; 10.6)$. We did not reveal any gender peculiarities in our study. Family history of immune-mediated diseases is found in $5 / 75(6.7 \%)$ in prospective group. Concomitant immune-mediated diseases were noted in $62 / 89(68.1 \%)$. Diagnostic delay was $6.3(2.0 ; 17.8)$ 